DOI: https://doi.org/10.24127/ajpm.v10i3.4014

\title{
PENGEMBANGAN BAHAN AJAR MATERI KUBUS BERDASARKAN PENDEKATAN OPEN ENDED BERBANTUAN GEOGEBRA
}

\author{
Ani Agustianingsih ${ }^{1}$, Lusiana $^{2^{*}}$, Nila Kesumawati ${ }^{3}$ \\ 1,2*3 Pendidikan Matematika, Unversitas PGRI Palembang, Palembang, \\ Sumatera Selatan, Indonesia \\ Corresponding author: Jl. Jend A.Yani, Lorong Gotong Royong, 9/10 Ulu 30251, Palembang, Indonesia \\ E-mail: aniagustiaa4455@ gmail.com $^{1)}$ \\ luu.sii.ana@gmail.com ${ }^{2 *}$ \\ nilakesumawati@univpgri-palembang.ac.id ${ }^{3)}$
}

Received 17 July 2021; Received in revised form 12 September 2021; Accepted 17 September 2021

\begin{abstract}
Abstrak
Penelitian ini bertujuan untuk menghasilkan suatu produk bahan ajar materi bangun ruang sisi datar pokok bahasan kubusberdasarkan pendekatan Open Endded yang valid dan praktis dengan berbantuan geogebra untuk siswa SMP kelas VIIIberdasarkan model pengembangan ADDIE (Analysis, Design, Development, Implementation dan Evaluation). Subjek dalam penelitian ini adalah siswa kelas VIII yang berada di Desa Muara Burnai I, Kecamatan Lempuing Jaya, Kabupaten Oki yang berjumlah 15 orang. Pe ngumpulan data dilakukan melalui lembar angket validasi dan lembar angket respon siswa. Teknik analisis data dilakukan secara deskriftif kuantitatif.. Dari proses pengembangan menghasil data kevalidan dan data kepraktisan bahan ajar. Setelah data dianalisis menunjukan bahwa bahan ajar yang telah dikembangkan dikategorikan valid dengan perolehan nilai rata-rata kevalidan sebesar 97,22\% dan dikategorikan praktis dengan perolehan nilai rata-rata kepraktisan sebesar 93,6\%.Melalui proses pengembangan menghasilkan dua jenis bahan ajar yaitu bahan ajar cetak berupa LKS yang berisi langkah penggunaan dan bahan ajar non cetak berupa soft file dalam aplikasi geogebra.
\end{abstract}

Kata Kunci: Bahan ajar; geogebra; pengembangan.

\begin{abstract}
This study aims to produce a product of teaching materials for the flat side of the cube subject based on a valid and practical Open Endded approach with the help of Geogebra for class VIII SMP students based on the ADDIE development model (Analysis, Design, Development, Implementation and Evaluation). The subjects in this study were class VIII students who were in Muara Burnai I Village, Lemrub Jaya District, Oki Regency, totaling 15 people. Data collection was carried out through a validation questionnaire sheet and a student response questionnaire sheet. The data analysis technique was carried out in a quantitative descriptive manner. From the development process, it produced data on the validity and practicality of teaching materials. After the data was analyzed, it showed that the teaching materials that had been developed were categorized as valid with an average validity score of $97.22 \%$ and were categorized as practical with an average practicality score of 93.6\%. Through the development process, two types of teaching materials were produced, namely printed teaching materials in the form of worksheets containing steps for use and non-printed teaching materials in the form of soft files in the geogebra application.
\end{abstract}

Keywords: Development; geogebra; teaching materials.

This is an open access article under the Creative Commons Attribution 4.0 International License

\section{PENDAHULUAN}

Ilmu pengetahuan dan teknologi dari masa ke masa mengalami perkembangan yang sangat pesat. Sejalan dengan kemajuan ilmu pengetahuan dalam era media dan teknologi, penggunaan komputer juga semakin 
luas, termasuk juga dalam dunia pendidikan (Tanzimah, 2019).

Dalam proses pembelajaran guru dituntut aktif dan kreatif dalam menyampaikan pembelajaran sehingga peserta didik tidak merasa bosan saat belajar. Terdapat banyak penelitian yang terkait dengan pembelajaran matematika menggunakan Geogebra yang dilakukan oleh (Melilana et al., 2018; Asdarina \& Khatimah, 2021; Asmar \& Delyana, 2020; Fitriyani \& Sugiman, 2014; Nisiyatussani et al., 2018; Octariani \& Rambe, 2018; Ramdhani, 2017; Sari et al., 2016; Supriadi, 2015). Dari beberapa penelitian tersebut menyatakan bahwa Geogebra sangat bermanfaat dan memudahkan peserta didik dalam belajar matematika khususnya materi Geometri. Namun dari beberapa penelitian tersebut belum ada yang mengembangakan bahan ajar dalam bentuk softfile dan hardfile sekaligus untuk digunakan dalam proses belajar mengajar menggunakan suatu pendekatan pembelajaran khususnya pendekatan open ended.

Softfile dan hardfile yang akan dikembangkan didasari oleh hasil wawancara dengan salah satu guru mata pelajaran matematika pada salah satu SMP di Lempuing Jaya Okimeyatakan bahwa materi pada siswa SMP yang menjadi momok bagi mereka adalah Bangun Ruang. Pada mata pelajaran matematika secara garis besar memilik 4 (empat) yaitu aritmatika, aljabar, geometri, dan analisis. Menurut (Rohati, 2011) salah satu materi geometri pada SMP adalah materi bangun ruang. Perkembangan teknologi yang terjadi saat ini, guru diharapkan dapat memanfaatkan perkembangan teknologi untuk mengembangkan media pembelajaran berbasis ICT (Information and Communication Technology).
Pemanfaatan tekonologi pada proses belajar mengajar biasanya menggunakan komputer atau Laptop (Asdarina \& Khatimah, 2021). Siswa diabad ke-2 ini sudah familiar dengan teknologi yang harus digukanakan untuk menunjang proses pembelajaran seperti laptop, komputer, internet, handphone, dan lain-lain. (Korenova, 2017)

Bahan ajar yang sedang trending pada saat ini adalah bahan ajar yang dapat digunakan untuk menunjang proses pendidikan merupakan suatu bahan ajar yang mampu digunakan dalam kondisi apapun, baik digunakan dalam pembelajaran langsung maupun pembelajaran jarak jauh, baik daring maupun luring (Nugroho, Badawi, \& Prihatmojo, 2021). Seiring dengan itu, saat ini sudah banyak software yang dapat dimanfaatkan untuk dunia pendidikan, termasuk pendidikan matematika sekolah. Salah satu software yang dapat dikembangkan untuk proses pembelajaran adalah software GeoGebra. Geogebra diciptakan untuk membantu siswa memperoleh pemaha-man yang lebih baik dalam matematika. Pendidik dapat menggunakan Geogebra untuk mengajar yang berorientasi pada masalah matematika serta mendorong siswa untuk melakukan percobaan baik disekolah mauun diluar sekolah. Geogebra dapat digunakan baik sebagai pembelajaran maupun sebagai alat untuk belajar (Ekawati, 2016).

Selain bantuan alat, pemilihan pendekatan dalam pembelajaran yang tepat juga berpengaruh pada siswa agar mereka benar-benar merasakan makna yang dipelajari (Octariani \& Rambe, 2018). Dalam penelitian menggunakan salah satu pendekatan Open-Ended. Menurut (Soeyono, 2014) mengungkapkan bahwa penggunaan pendekatan dalam pembelajaran Open-Ended 
DOI: https://doi.org/10.24127/ajpm.v10i3.4014

matematika dapat meningkatkan berpikir kritis dan kreatf pada siswa. Pendekatan pembelajaran Open-Ended memiliki karakteristik yaitu dengan menyajikan permasalahan terbuka pada awal permasalahan yang memiliki beberapa jawaban.

Oleh karena itu, tujuan penelitian ini adalah untuk menghasilkan suatu pengembangan bahan ajar materi kubus berdasarkan pendekatan Open Ended berbantuan Geogeba pada siswa SMP/Mts kelas VIII yang valid dan praktis.

\section{METODE PENELITIAN}

Penelitian ini menggunakan metode penelitian dan pengembangan (reseach and development) yang menitikberatkan pada pengembangan bahan ajar. Penelitian dan pengembangan merupakan suatu proses yang harus dilakukan untuk mendapatkan suatu produk. Dalam melakukan suatu pengembangan, tentunya tak luput dari model pengembangan yang digunakan.

Model yang digunakan dalam penelitian dan pengembangan ini adalah model pengembangan ADDIE (analysis, design, development, implementation, dan evaluation (Branch, 2009). Dalam tahap analysis yang dilakukan adalah menganalisis Kurikulum 2013 (K13), menganalisis siswa, dan menganalisis materi.

Tahap selanjutnya adalah Design. Ada beberapa hal yang dilakukan dalam membuat design diantaranya cover, materi, langkah-langkah kegiatan, contoh soal, dan pemilihan format. Pemilihan format yang dilakukan dengan memilih format bahan ajar cetak dan bahan ajar non cetak. Desain awal yang telah dilakukan disebut dengan prototype $I$.

Proses selanjutnya adalah

Development. Tahap ini merupakan tahap pengembangan dengan dilakukannya validasi terhadap prototype $I$ kepada 3 (tiga) ahli atau validator. Selanjuntnya dikukan revisi sesuai dengan kritik dan saran dari validator hingga menghasilkan prototype II. Tahap Implementation dengan melakukan uji coba one to one kepada 3 (tiga) orang siswa yang berada dilingkungan peneliti, tetapi siswa tersebut merupakan siswa dari sekolah yang berbeda. Hal ini dilakukan untuk mengetahui bagian-bagian bahan ajar yang perlu direvisi dari responden.

Dalam tahap uji coba one to one, siswa memberikan beberapa masukan kemudian menghasilkan prototype III. Selanjutnya dilakukan uji coba small group kepada 5 (lima) orang siswa dari sekolah yang beda yang berada di Desa Muara Burnai I sebagai responden yang bertujuan untuk mengetahui respon dari hasil revisi tahap one to one. Dari uji coba small Group yang telah dilakukan, tidak ditemukan saran untuk dilakukannya perbaikan. Kemudian, dilakukan kembali uji coba kepada 7 (tujuh) orang siswa (kelompok besar) yang berada di lingkungan peneliti. Hal ini dilakukan untuk mengetahui adanya efek potensial terhadap bahan ajar yang telah dikembangkan.

Tahap terakhir yang dilakukan adalah Evaluation. Evaluasi dalam hal ini terjadi disetiap kali tahap-tahap pengebangan. Setelah dilakukannya beberapa kali uji coba, maka terdapat beberapa evaluasi terhadap bahan ajar yang telah dikembangkan.

Subjek penelitian ini adalah siswa kelas VIII yang berada di Desa Muara Burnai I, Kecamatan, Lempuing Jaya, Kabupaten Oki. Produk yang telah di kembangkan akan di uji cobakan kepada 15 siswa kelas VIII sebagai responden uji coba one to one, small group dan kelompok besarpada setiap 
uji coba dilakukan maka berbeda jumlah siswa yang di uji cobakan yaitu 3 siswa pad uji coba one to one, 5 siswa pada uji coba small group, dan 7 siswa pada uji coba kelompok besar. Hal ini dilakukan untuk mengukur kepraktisan dari bahan ajar dari setiap hasil uji coba. Uji coba kelompok besar merupakan uji coba terakhir yang dilakukan untuk lebih mengetahui kapraktisan bahan ajar. Hal ini dilakukan hanya pada 7 orang siswa karena terkendala alat (laptop) yang teredia.

Teknik analisis data yang digunakanadalah data kuantitatif.Data yang dianalsis berupa lembar angket validasi untuk mengukur dan mengetahui kevalidan dari bahan ajar yang telah dikembangkan, serta analsis data lembar angket respon siswa yang digunakan untuk mengukur dan mengetahui kepraktisan bahan ajar yang telah digunakan. Kriteria penilaian dalam lembar validasi terdiri dari beberapa aspek pilihan jawaban. Adapun skor dalam skala penilaian lembar angket validasi dapat dilihat pada Tabel 1.

Tabel 1. Kriteria Penilaian Validasi

\begin{tabular}{cl}
\hline Skor & \multicolumn{1}{c}{ Kriteria Validasi } \\
\hline 4 & Sangat Baik/Valid \\
3 & Baik/Cukup Valid \\
2 & Kurang Baik/Kurang Valid \\
1 & Sangat Kurang Baik/ Tidak Valid \\
\hline
\end{tabular}

Adapun criteria penilain dalam lembaran alisis angket respon siswa terdiri dari beberapa aspek pemilihan jawaban dapat dilihat pada Tabel 2.

Tabel 2. Kriteria Skor Angket Siswa

\begin{tabular}{cc}
\hline Kriteria Jawaban & Skor \\
\hline SS (Sangat Setuju) & 5 \\
S (Setuju) & 4 \\
CS (Cukup Setuju) & 3 \\
KS (Kurang Setuju) & 2 \\
TS (Tidak Setuju) & 1 \\
\hline
\end{tabular}

Data yang telah diperoleh dar lembar angket validasi dan lembar angket respon siswa kemudian dilakukan analisis dengan jumlah skor yang diperoleh bagi dengan jumlah skor keseluruhan dan dikalikan 100. Adapun rumus yang digunakan adalah sebagai berikut.

$$
\mathrm{N}=\frac{\Sigma a}{\Sigma b} \times 100
$$

Keterangan:

$\mathrm{N}$ : nilai

$\Sigma a$ : Jumlah Skor Yang Diperoleh

$\Sigma b$ : Jumlah Skor Tertinggi

Presentase tanggapan responden dapat dilihat sesuai dengan kriteria interprestasi skor yang disajikan dalam skala likert pada Tabel 3.

Tabel 3. KriteriaInterpretasiSkor

\begin{tabular}{|c|c|c|}
\hline No & Persentase (\%) & Keterangan \\
\hline 1. & $0-49,99$ & $\begin{array}{lrr}\text { Sangat Tidak } & \text { Baik/ } \\
\text { Tidak Valid/ } & \text { Tidak } \\
\text { Menarik } & \end{array}$ \\
\hline 2. & $50,00-59,99$ & $\begin{array}{l}\text { Kurang Baik/Kurang } \\
\text { Valid/Kurang } \\
\text { Menarik }\end{array}$ \\
\hline 3. & $60,00-79,99$ & $\begin{array}{l}\text { Baik/Cukup } \\
\text { Valid/Menarik }\end{array}$ \\
\hline 4. & $80,00-100$ & $\begin{array}{l}\text { Sangat } \\
\text { Baik/Valid/Sangat } \\
\text { Menarik }\end{array}$ \\
\hline
\end{tabular}

\section{HASIL DAN PEMBAHASAN}

Dari setiap tahap yag dilakukan tentunya memiliki penjelasan terkait hasil dari penelitian. Berikut hasil dan pembahasan dari penelitian yang telah dilakukan.

\section{A. Analysis}

Dalam tahap analisis, terdapat beberapa hal yang perlu dilakukan analsis meliputi: analisis kurikulum, analisis silabus, analisis materi, dan analisis siswa. Dalam analisis kurikulum, hal yang perlu diperhatikan adalah kurikulum yang berlaku pada satuan pendidikan yaitu Kurikulum 
2013 (K13). Selanjutnya, untuk analisis silabus, mata pelajaran pada tingkat SMP dan MTs. Kemudian, untuk analisis materi harus sama dengan analisis kurikulum yang digunakan. Materi yang digunakan untuk mengembangkan bahan ajar yaitu bangun ruang sisi datar serta menanalisis pokok bahasan yang akan dikembangkan yait Kubus. Terakhir, analisis siswa, menurut (Aspriyani \& Suzana, 2020) analsis siswa dilakukan untuk mengetahui karakteristik siswa, kemampuan siswa, serta minat siswa dalam mata pelajaran matematika masih menganggap matematika sulit dipalajari.

\section{B. Design}

Dalam tahap ini, dilakukan pendesaian terhadap bahan ajar yang akan dikembangkan, mulai dari bahan cover, isi, kegiatan, serta aplikasi yang digunakan. Tahap awal pendesaian dilakukan sesuai dengan penilaian diri sendiri terhadap bahan ajar yang dikembangkan dan menghasilkan prototype I. Contoh dari tampilan bahan ajar awal yang telah dilakukan penilaian pribadi dapat dilihat pada Gambar 1 .

Gambar 1 merupakan tampilan awal dari cover LKS yang merupakan bahan ajar cetak. LKS tersebut merupakan suatu langkah-langkah atau petunjuk penggunaan yang disajikan secara tertulis untuk mengaplikasikan bahan ajar yang terdapat didalam aplikasi geogebra. Kemudian, Gambar 2 merupakan tampilan dari bahan ajar noncetak atau bahan ajar yang terdapat didalam aplikasi geogebra. Geogebra 1 merupakan tampilan bahan ajar yang berisi materi materi yang disajikan dalam bentuk animasi. Berikutnya, Gambar 3 merupakan tampilan dari bahan ajar dalam aplikasi Geogebra yang akan digunakan untuk mencari luas dan volume kubus yang ditentukan oleh panjang rusuk kubus. Dalam bentuk dan tampilan kubus menggunakan animasi atau gerakangerakan kubus yang sesuai dengan panjang kubus yang ditentukan.

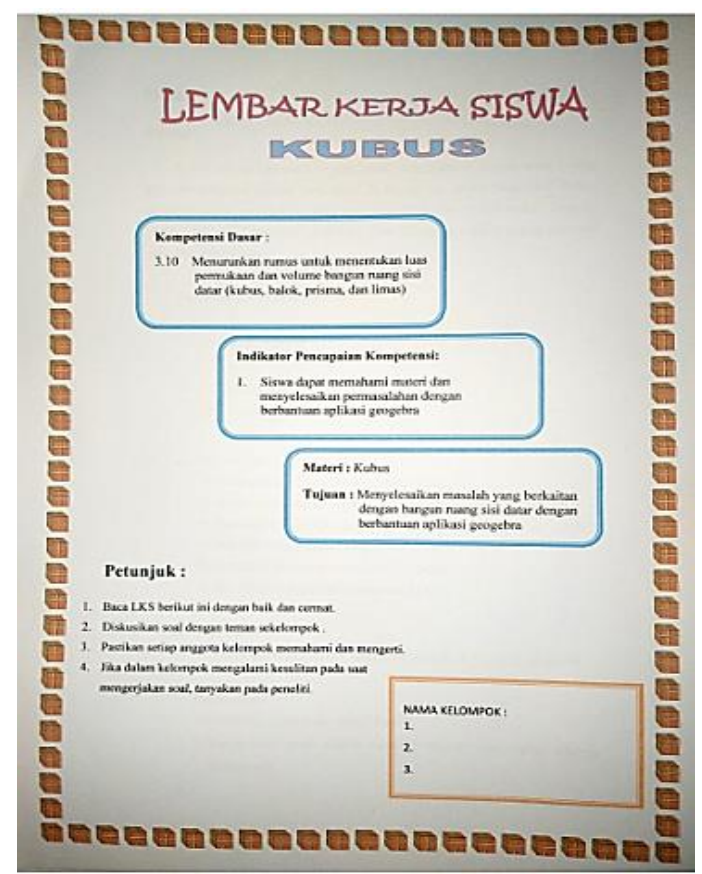

Gambar 1.Tampilan cover bahan ajar cetak

\section{Development}

Setelah menghasilkan prototype I, maka dilakukan validasi kepada pakar/ahli pada bidangnya atau disebut dengan validator. Hal ini dilakukan guna untuk mendapatkan penilaian, komentar, saran, atau masukan yang dilakukan kepada tiga validator yang merupan dua orang dosen ahli media dan ahli materi, serta seorang guru mata pelajaran di SMP/MTs ditempat penelitian. Setelah dilakukannya revisi maka menghasilkan prototype IIyang selanjutnya dilakukan validasi kembali dengan memberikan lembar angket validasi untuk melakukan penilain dari hasil revisi (prototype II). Berikut table analisis lembar angket validasi kepada 3(tiga) validator: 
DOI: https://doi.org/10.24127/ajpm.v10i3.4014

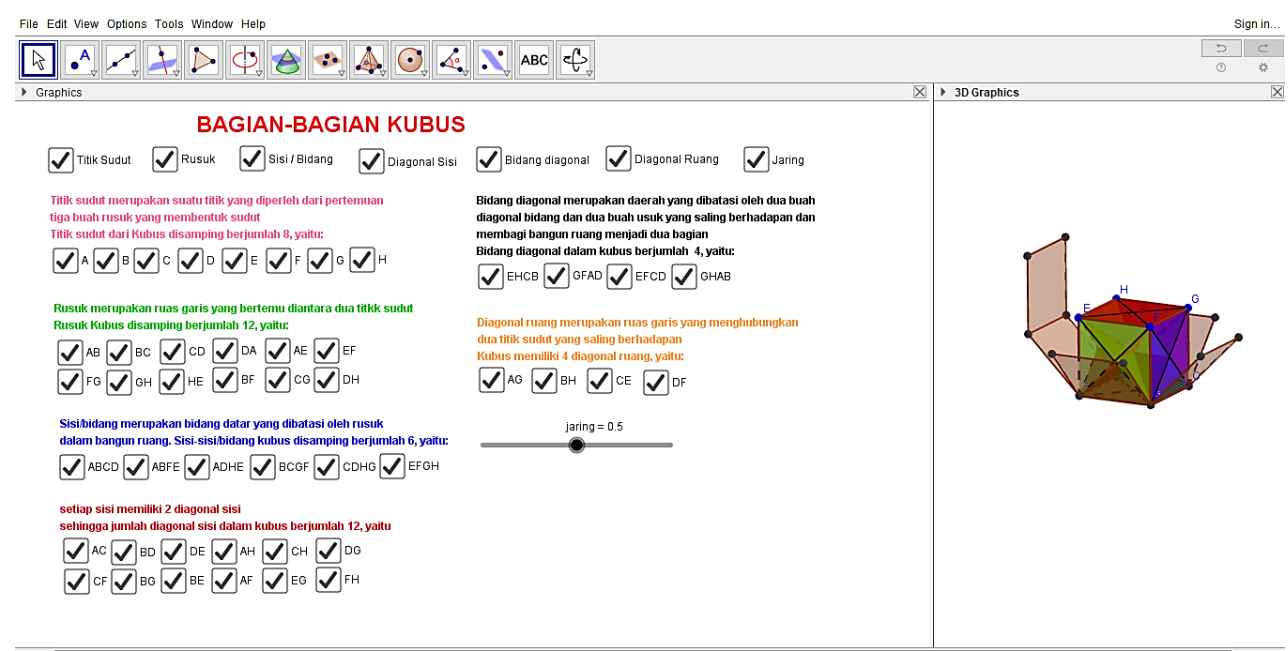

Gambar 2. soft file bahan ajar a

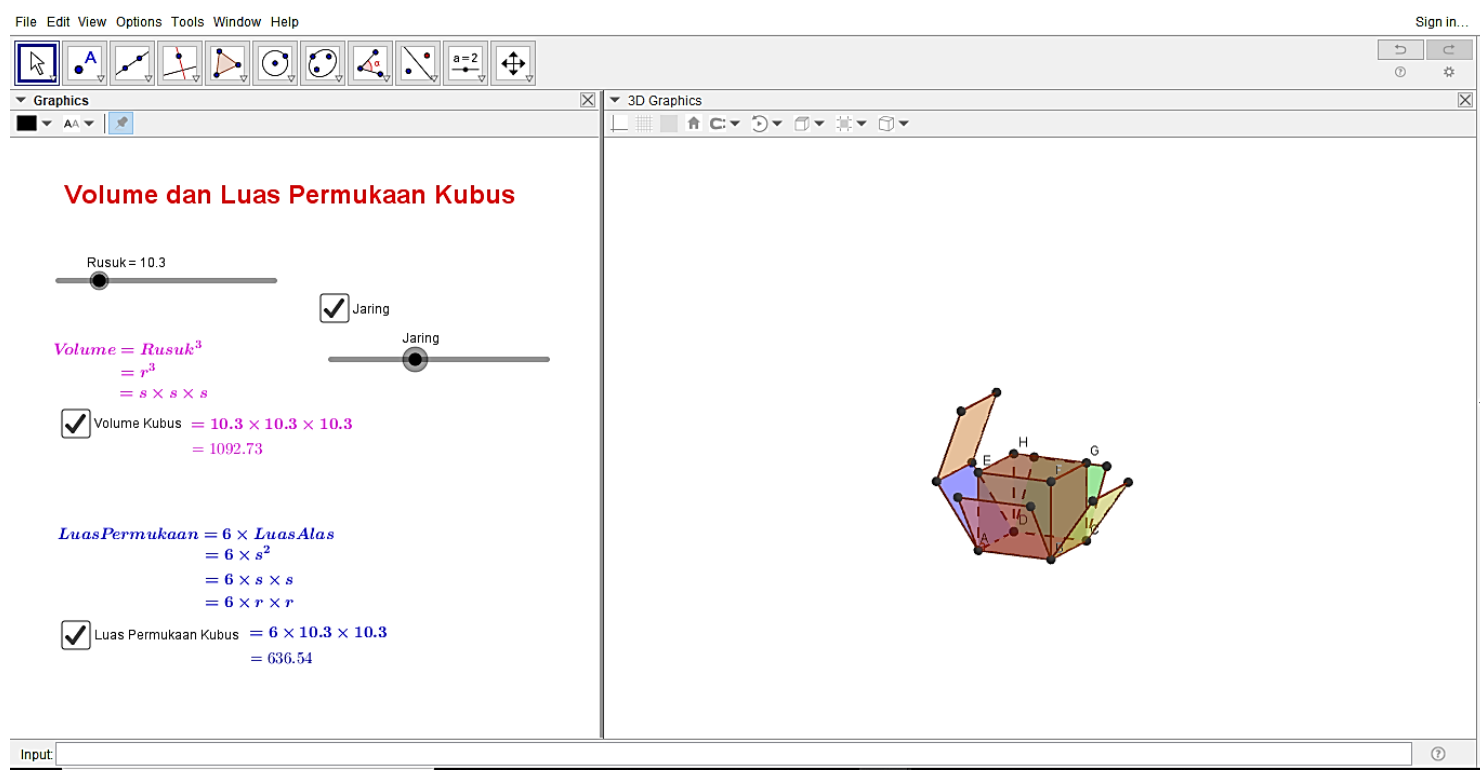

Gambar 3. soft file bahan ajar b

Tabel 4. Analisis Hasil Angket Validasi

\begin{tabular}{lcc}
\hline No & Validator & $\begin{array}{c}\text { Rata- Rata } \\
\mathbf{( \% )}\end{array}$ \\
\hline 1. & Validator 1 & 96,67 \\
2. & Validator 2 & 98,33 \\
3. & Validator 3 & 96,67 \\
\hline & Jumlah & $\mathbf{2 9 1 , 6 7}$ \\
\hline & Rata-Rata & $\mathbf{9 7 , 2 2}$ \\
\hline
\end{tabular}

Secara umum data yang didapat dari lembar angket validasi memperoleh nilai rata-rata yang diperoleh dari para validator sebesar $97,22 \%$, sehingga memenuhi kriteria valid. Berdasarkan hasil validasi yang telah didapat, maka bahan ajar yang telah dikembangkan layak untuk digunakan.

\section{Implementation}

Dalam tahap implementation ini terdapat beberapa tahap uji coba prototype II terhadap siswa sebagai responden diantaranya one to one, smal group, dan kelompok besar.

\section{1) One to one}

Tahap One to one dilakukan kepada tiga orang siswa SMP/MTs kelas VIII yang berbeda sekolah di Dusun VI Rt 02 desa Muara Burnai I. 
DOI: https://doi.org/10.24127/ajpm.v10i3.4014

Sejalan dengan dilakukannya uji coba one to one, juga memberikan angket respon siswa untuk memberikan suatu penilaian serta tangapan terhadap bahan ajar (prototype II) yang digunakan. Dari uji coba one to one sehingga menghasilkan bahan ajar yang harus direvisi sesuai dengan komentar atau saran dari responden. Setelah dilakukan revisi, maka terbentuklah prototype III.

\section{2) Small group}

Setelah menghasilkan prototype III, kemudian dilakukan uji coba kepada lima orang siswa SMP/MTs kelas VIII yang berbeda sekolah di Dusun VI Rt 06 Desa Muara Burnai 1. Sejalan dengan dilakukannya uji cobajuga diberikan lembar angket respon siswa untuk memberikan penilaian serta tanggapannya terhadap prototype III yang digunakan untuk mengetahui kepraktisan dari prototype III. Hasil dari uji coba small group berupa komentar siswa yang menyatakan bahwa bahan ajar yang dikembangkan menarik dan baik untuk digunakan.

\section{3) Kelompok Besar}

Dalam uji coba kelompok besar dilakukan kepada siswa SMP/MTs kelas VIII yang berada di Dusun IV RT 02 Desa Muara Bunai I. Dalam uji coba ini berjumlah tujuh orang dengan siswa yang beda sekolah pada tempat penelitian. Setelah uji coba selesai, maka diberikan lembar angke trespon siswa untuk mendapatkan penilaian terhadap prototype III yang telah diujicobakan.

Setelah lembar angket respon siswa dianalisis pada bagian tanggapan dan saran yang diberikan dengan hasil yang lebih mengarah kepada pendapat mereka mengatakan bahwa bahan ajar atau prototype III baik untuk digunakan, hal ini sesuai dengan hasil analisis nilai rata-rata dari keseluruhan angket respon siswa yang telah dianalisis.
Untuk penilaian kepraktisan bahan ajar yang digunakan adalah lembar angket respon siswa dengan jumlah 15 butir pernyataan. Setiap angket tersebut diberikan kepada masing-masing siswa yang berjumlah 15 orang siswa dengan rincian 3 orang siswa uji coba one to one, 5 orang siswa pada uji coba small group, dan 7 orang siswa pada uji coba kelompok besar. Dari hasil analisis data pada lembar angket respon siswa di peroleh persentase nilai rata-rata sebesar $93,6 \%$.

Berdasarkan uraian diatas, menyatakan bahwa criteria interpretasi skor sangat praktis berada pada interval 80,00\%-100\%. Hal ini sejalan dengan penelitian yang dilakukan oleh (Mahuda, Suhamah, Nasrullah, \& Junaedi, 2020) yang menyatakan bahwa hasil pengembangan bahan ajar berbasis vlog memperoleh nilai rata-rata kepraktisan sebesar 83\%, sehingga dapat ditarik kesimpulan bahwa bahan ajar yang telah dikembangkan masuk kedalam tingkat bahan ajar yang sangat praktis.

Berdasarkan Tabel 4 yang menyatakan bahwa hasil analisis lembar angket validasi oleh validator diperoleh persentase nilai rata-rata sebesar 97,22\%, hal ini membuktikan bahwa bahan ajar yang telah dikembangkan adalah valid dengan diperkuat oleh penelitian sebelumnya yang dilakukan oleh (Melilana et al., 2018) yang menghasilkan media pembelajaran dengan menggunakan GeoGebra yang valid dengan kriteria kevalidan yang diperoleh dari angket validasi media sebesar $95,51 \%$, dalam hal ini bahan ajar yang telah dikembangkan dapat dikegorikan valid.

Dalam melakukan penelitian ini, terdapatbeberapa kendala yaitu pada saat penelitian ini berlangsung, dalam penelitian ini tidak bisa melakukan 
disekolahan karena adanya pandemi Covid-19.(Loviana \& Baskara, 2020) mengungkapkan bahwa adanya pandemic Covid-19 yang mengharuskan sekolah-sekolah dimanapun menggunakan sistem belajar dirumah dan dilaksanakan secara online atau daring. Selama penelitian ini berlangsung, peneliti tidak lupa untuk tetap mematuhi dan melaksakan protokol kesehatan dengan menggunakan masker, mencuci tanga, menggunakan hand sanitaizer, serta jaga jarak antar siswa. Mengingat pandemi Covid-19 ini belum berlalu dan masih menjadi momok yang manakutkan bagi masyarakat setempat, maupun masyarakat global.

\section{E. Evaluation}

Pada tahap ini, evaluasi dilakukan mulai dari tahap pendesaian sampai dengan implementation yang bertujuan untuk mengetahui respon kevalidan dari para validator kepraktisan siswa terhadap bahan ajar yang telah dikembangkan. Berdasarkan uraian diatas, maka dapat ditarik kesimpulan bahwa bahan ajar materi kubus berdasarkan pendekatan Open-Ended berbantuan geogebra pada siiswa kelas VIII ditinju dari aspek kevalidan dan kepraktisan dapat dikategorikan sebagai bahan ajar yang valid dan praktis.

Proses penilaian ini sejalan dengan penelitian yang dilakukan oleh (Agitsna, Wahyuni, \& Friansah, 2019), perbedaannya terletak pada penggunaan model pembelajran dan materi yang diajarkan. Penelitian ini sejalan dengan penelitian yang dilakukan oleh (Ramdhani, 2017) dengan hasil pengembangan media pembelajaran konsep luas bidang datar berbasis perangkat lunak Geogebra secara luas untuk MTs di Kabupaten Bandung yang menghasilkan media pebelajaran yang valid dan praktis.
Untuk dapat melihat hasil dari penelitian yang dilakukan, dapat mengakes link berikut:

Hardfile:

https://drive.google.com/file/d/13Kh3u wauTowyxi5YGAvUwlJm4duYoGhj/vi ew?usp=sharing

Softfile :

1) https://drive.google.com/file/d/1OXS Ilgq_DMNf4B9o0Sd82gmxlVrP821/view?usp=s haring

2) https://drive.google.com/file/d/1uxg2 vKs8Ki7Bj2yht5spI044i8Sf3ux_vie w?usp=sharing

\section{KESIMPULAN DAN SARAN}

Berdasarkan hasil penelitian yang telahd ilakukan, maka dapat ditarik kesimpulan bahwa bahan ajar yang telah di kembangkan dengan menggunakan bantuan geogebra menghasikan bahan ajar yang valid dan praktis untuk proses pembelajaran dengan hasil persentase rata-rata nilai kevalidan sebesar $97,22 \%$ dan persentase nilai rata-rata kepraktisan sebesar 93,6\%.

Saran yang dapat diberikan adalah untuk memanfaatkan bahan ajar yang telah dikemangkan ini agar para pendidik atau peserta didik dapat memanfaatkan bahan ajar ini pada masa pandemi Covid-19 yang dimana proses pembelajaran dilakukan secara jarak jauh secara online atau daring. Kemudian untuk peneliti lain dapat mengembangkan bahan ajar ini pada materi matematika yang lainya agar dapat dianfaatkan oleh khalayak lain.

\section{DAFTAR PUSTAKA}

Agitsna, L. D., Wahyuni, R., \& Friansah, D. (2019). Pengembangan Lembar Kerja Siswa Berbasis Problem Based Learning Pada Materi Bangun 
DOI: https://doi.org/10.24127/ajpm.v10i3.4014

Ruang Sisi Datar. AKSIOMA: Jurnal Program Studi Pendidikan Matematika, 8(3), 429-437. https://doi.org/10.24127/ajpm.v8i3. 2360

Asdarina, O., \& Khatimah, H. (2021). Pengembangan Modul Pembelajaran Matriks Berbantuan Aplikasi Geogebra. AKSIOMA: Jurnal Program Studi Pendidikan Matematika, 10(2), 860-871.

Asmar, A., \& Delyana, H. (2020). Berpikir Kritis Melalui Penggunaan Software Geogebra. AKSIOMA: Jurnal Program Studi Pendidikan Matematika, 9(2), 221-230.

Aspriyani, R., \& Suzana, A. (2020). Pengembangan E-Modul Interaktif Materi Persamaan Lingkaran Berbasis Realistic Mathematics Education Berbantuan Geogebra. AKSIOMA: Jurnal Program Studi Pendidikan Matematika, 9(4), 1099.

https://doi.org/10.24127/ajpm.v9i4. 3123

Branch. (2009). Instructional Design: The ADDIE. Approach Springer.

Ekawati, A. (2016). Penggunaan Software Geogebra dan Microsoft Mathematic dalam Pembelaran Matematika. Math Didactic: Jurnal Pendidikan Matematika, 2(3), 148-153.

Fitriyani, W., \& Sugiman, S. (2014). Pengembangan Perangkat Pembelajaran Teorema Pythagoras Dengan Pendekatan Ideal Berbantuan Geogebra. Jurnal Riset Pendidikan Matematika, 1(2), 268-283.

https://doi.org/10.21831/jrpm.v1i2. 2681

Latifah, S., Setiawati, E., \& Basith, A. (2016). Pengembangan Lembar Kerja Peserta Didik (LKPD)
Berorientasi Nilai-Nilai Agama Islam melalui Pendekatan Inkuiri Terbimbing pada Materi Suhu dan Kalor. Jurnal Ilmiah Pendidikan Fisika Al-Biruni, 5(1), 43-51. https://doi.org/10.24042/jpifalbirun i.v5i1.104

Loviana, S., \& Baskara, W. N. (2020). Dampak Pandemi Covid-19 Pada Kesiapan Pembelajaran Tadris Matematika Iain Metro Lampung. Journal Epsilon, 2(1), 62-70.

Mahuda, I., Suhamah, A., Nasrullah, A., \& Junaedi, B. (2020). Pengembangan Bahan Ajar Matematika Ekonomi Berbasis VLog Berorientasi Pada Kemampuan Penguasaan Konsep dan Komunikasi Matematis. AKSIOMA: Jurnal Program Studi Pendidikan Matematika, 9(3), 516-529.

Melilana, P., Krisdiana, I., \& Setyansah, R. K. (2018). Pengembangan Media Pembelajaran dengan Menggunakan Geogebra pada Pelajaran Matematika Pokok Bahasan Bangun Ruang. Prosiding Silogisme, (1). Universitas PGRI Madiun. Retrieved from http://prosiding.unipma.ac.id/index .php/PSNPM/article/view/615

Nisiyatussani, Ayuningtyas, V., Fathurrohman, M., \& Anriani, N. (2018). GeoGebra applets design and development for junior high school students to learn quadrilateral mathematics concepts. Journal on Mathematics Education, 9(1), 27-40.

Nugroho, P. B., Badawi, \& Prihatmojo, A. (2021). Pengembangan Bahan Ajar Berbentuk Video Pembelajaran Berbasis Data Covid-19 Untuk Meningkatkan Kewaspadaan Mahasiswa Terhadap Hoaks. Aksioma: Jurnal 
DOI: https://doi.org/10.24127/ajpm.v10i3.4014

Matematika Dan Pendidikan Matematika, 10(2), 467-478.

Octariani, D., \& Rambe, I. H. (2018). Pengembangan Bahan Ajar Berbasis Project Based Learning Berbantuan Software Geogebra. MES: Journal of Mathematics Education and Science, 4(1), 1621.

https://doi.org/10.30743/mes.v4i1. 864

Ramdhani, S. (2017). Pengembangan Media Pembelajaran Konsep Luas Bidang Datar Berbasis Perangkat Lunak Geogebra. JES-MAT (Jurnal Edukasi Dan Sains Matematika), 3(2), 95. https://doi.org/10.25134/jesmat.v3i2.684

Rohati. (2011). Pengembangan Bahan Ajar Materi Bangun Ruang dengan Menggunakan Strategi Relating, Experiencing, Applying, Cooperating, Transferring (REACT) Di Sekolah Menengah Pertama. EDUMATICA, 01(02), 61-73.

Sari, F. K., Farida, \& M.Syazali. (2016). Pengembangan Media Pembelajaran (Modul) berbantuan Geogebra Pokok Bahasan Turunan. Jurnal Pendidikan Matematika, 7(2), 135-152. Retrieved from http://ejournal.radenintan.ac.id/ind ex.php/al-jabar/article/view/24

Soeyono, Y. (2014). Pengembangan Bahan Ajar Matematika dengan Pendekatan Open-ended untuk Meningkatkan Kemampuan Berpikir Kritis dan Kreatif Siswa SMA. Phytagoras: Jurnal Pendidikan Matematika, 9(2), 205-218.

Supriadi, N. (2015). Pembelajaran Geometri Berbasis Geogebra Sebagai Upaya Meningkatkan Kemampuan Komunikasi
Matematis. Al-Jabar: Jurnal Pendidikan Matematika, 6(2), 99109. Retrieved from http://ejournal.upi.edu/index.php/jp manper/article/view/00000\%0AIm pak

Tanzimah. (2019). Pemanfaatan geogebra dalam pembelajaran matematika. Prosiding Seminar Nasional, 610-616. Palembang: Universitas PGRI Palembang. Retrieved from https://jurnal.univpgripalembang.ac.id/index.php/Prosidi ngpps/article/view/3091 